\title{
El consumidor y su importancia en otras disciplinas del Derecho mercantil ${ }^{1}$
}

\author{
FideL PuENTES SiLVA ${ }^{2}$
}

\section{RESUMEN}

El desarrollo histórico de algunas disciplinas del derecho mercantil como la propiedad industrial, la competencia desleal o la libre competencia nos permite concluir que, en la actualidad, surgen como elementos esenciales protegidos por las mismas no solo los intereses de los competidores y/o los intereses públicos del Estado, sino los intereses colectivos de los consumidores, y que ningunos son tan relevantes como estos últimos, justamente por su relación directa con la noción de dignidad humana y su relevancia en un estado social de derecho como el nuestro. De este modo, lo que se exige de los involucrados, es que los análisis pasen de lo conceptual a lo material en procura de considerar al consumidor como eje transversal de los objetivos mercantilistas, aun cuando las controversias se enmarquen en reglas que en principio custodian otros bienes jurídicamente tutelados como la libre y sana competencia económica y los derechos de propiedad industrial.

Palabras clave: Consumidor, libre Competencia, Competencia Desleal, Propiedad Industrial.

1 Fecha de recepción: 3 de noviembre de 2017. Fecha de aceptación: 31 de enero de 2018. Para citar el artículo: PuENTES Silva, F. (2018). "El consumidor y su importancia en otras disciplinas del Derecho mercantil", en Revista Con-texto, n. ${ }^{\circ} 49$, pp. 209-225. DOI: https://doi.org/10.18601/01236458.n49.09

2 Abogado de la Universidad Pedagógica y Tecnológica de Colombia. Especialista en Derecho Financiero de la Universidad del Rosario y especialista en Derecho Comercial de la misma Universidad. Magíster en Propiedad Intelectual e Industrial de la Universidad de Barcelona y EAE Business School. Miembro del Instituto Colombiano de Derecho Procesal. Catedrático del Departamento de Derecho Procesal de la Universidad Externado de Colombia, del Departamento de Derecho Económico de la Pontificia Universidad Javeriana, entre otras. Ex Superintendente Delegado para Asuntos Jurisdiccionales de la Superintendencia de Industria y Comercio. Superintendente Delegado para la Protección del Consumidor. Correo-e: fidelpuentessilva@gmail.com 


\section{THE CONSUMER AND ITS IMPORTANCE ON OTHER DISCIPLINES IN BUSINESS LAW}

\section{ABASTRACT}

The historical development of some disciplines in Business Law such as the Industrial Property, the Unfair Competition or Free Competition allow us to conclude that, nowadays, emerge as essential elements protected by these disciplines not only the competitors and/or public state's interests but the collective consumers interests, which are more relevant because of its direct relation with the human dignity concept and its importance on a Social State based on the rule of law like ours. In this way, what it's required from the involved is that the analysis transcend from the conceptual to the factual in order to consider the consumer as the transversal axis of the commercial objectives, even when the disputes are framed in rules that at first contemplate other legally protected rights such as the free economic competition and the industrial property rights.

Keywords: Consumer, Free Competition, Unfair Competition, Industrial Property.

\section{INTRODUCCIÓN}

Los diferentes sistemas de obtención, configuración y alcance de los derechos de propiedad industrial se estructuraron, en principio, a partir del interés particular, representado en el conjunto de prerrogativas (ius utendi y ius probibendi) que el Estado confiere a una persona respecto de un determinado signo distintivo o nueva creación, entendiendo que de esta manera se producen efectos beneficiosos en el mercado y, en consecuencia, se favorece la economía de los países, pero también a los consumidores. Es así que, hoy por hoy, para la comunidad jurídica en general, resulta claro que el éxito y adecuado funcionamiento de los modelos de gestión de los derechos de propiedad industrial que se aplican en una determinada zona geográfica, finalmente representan beneficios para los consumidores pues, por citar uno de ellos, se propende a eliminar del sistema aquellos otros signos distintivos que podrían inducirlos a error al momento de materializar sus decisiones de consumo.

Así mismo, en la dinámica propia del ejercicio del Derecho en áreas como la Competencia Desleal o la Protección de la Competencia, el estudio de conceptos como el de libre concurrencia económica, así como el análisis del complejo fenómeno de interrelación entre los derechos y deberes de los operadores mercantiles que contienden por ganar un espacio en el mercado, constituyen el objeto central de estudio pero, al igual que en el caso anterior, académica y jurisprudencialmente hay unanimidad en cuanto a que, al final, la libre competencia y la supresión de conductas desleales en este campo producen mercados saludables en los que los principales beneficiados son los consumidores. 
Existe, entonces, la convicción generalizada de que robustos modelos de protección de la propiedad industrial y de promoción y protección de la libre y leal competencia terminan por beneficiar a los consumidores como un efecto colateral del adecuado funcionamiento del sistema, constituyéndose estos como uno de los intereses jurídicos tutelados en cada una de estas disciplinas del Derecho.

Así pues, la protección de los derechos e intereses de los consumidores constituye uno de los ejes de nuestro modelo social de competencia y del sistema de gestión de los derechos de propiedad industrial.

En efecto, las normas que dotan de contenido áreas del Derecho como las mencionadas, evidentemente se deben interpretar a la luz de los principios constitucionales y en el marco de nuestro modelo de Estado Social de Derecho, en el que se da prelación al interés general y en donde todas las instituciones deben girar en torno al concepto de dignidad humana y prevalencia de los derechos fundamentales de las personas, razón de suficiente peso para sostener, sin mayores cavilaciones, que el colectivo de consumidores debe constituir el objeto principal de protección en estas materias, atendiendo a la posición de debilidad en que este se encuentra frente a las demás fuerzas del mercado.

La comprensión detallada de nuestro modelo de regulación en áreas como la competencia y la propiedad industrial, así como la convicción profunda frente al altísimo valor que tiene el principio de protección de los derechos e intereses de los consumidores en dicho modelo, conduce a aproximaciones académicas e incluso jurisprudenciales en estas disciplinas del Derecho mercantil, con profundos y fructuosos análisis del mercado y sus complejas variables, haciendo que la figura del consumidor adquiera gran protagonismo no solo en el obiter dicta de los pronunciamientos, sino en la ratio decidendi de los mismos, ya que se emplea este criterio como un factor central y preponderante en el momento de resolver determinados asuntos.

El fenómeno así descrito no puede sino generar efectos materiales benéficos para el funcionamiento del modelo, pues aun aceptando que el interés de los competidores y el interés del Estado son pilares fundamentales de nuestro esquema de regulación del mercado, lo cierto es que el proceso de evolución de la regulación mercantil se ha decantado históricamente hasta llegar al actual modelo social en materia de competencia, en consonancia con el desarrollo de instituciones como el Estado Social de Derecho, en donde conceptos como el de la función social de la propiedad y, en este caso, la propiedad industrial como una especie del género, trascienden la esfera de lo privado e impactan de manera directa en los intereses colectivos, como los de los consumidores, motivo más que suficiente para afirmar que estos merecen una protección más elevada, convirtiéndose en el objeto principal de protección para las autoridades.

Ciertamente, el auge de los derechos de los consumidores se remonta al 15 de marzo de 1962, cuando el entonces presidente de Estados Unidos de América, JOHN F. KENNEDY, proclamó: "Por definición, consumidores somos todos. Este es el grupo económico más grande que afecta y es afectado por casi todas las decisiones económicas públicas y privadas. Sin embargo, constituyen a la vez el único grupo importante cuyas opiniones a menudo no son escuchadas". KENNEDY planteó cuatro principios básicos a 
manera de derechos de los consumidores: seguridad, información, elección y el derecho a ser escuchado.

El mundo vive por esa época un verdadero replanteamiento de los valores humanísticos, después de haber padecido los horrores de las guerras y en casi todo el planeta se ha formulado la discusión sobre un nuevo modelo de constitucionalismo en el que el principio de legalidad ya no se considera la máxima condicionante y reguladora per se y, por el contrario, se entiende sujeta a vínculos jurídicos de orden sustancial. Sobre el particular, Luigi Ferrajoli explicó que "La garantía jurídica de efectividad de este sistema de vínculos reside en la rigidez de las constituciones, asegurada a su vez, en las cartas constitucionales de la segunda posguerra (...) De esta manera, del derecho resulta positivizado no solamente su 'ser', es decir su existencia o vigor, sino también su 'deber ser', es decir sus condiciones de 'validez'; ya no solamente los vínculos formales relativos al 'quién' y al 'cómo' de las decisiones, sino también los vínculos de contenido relativos al 'qué cosa' de las decisiones mismas y que no son más que los principios y los derechos fundamentales: los derechos de libertad, que no pueden ser lesionados, y los derechos sociales cuyo cumplimiento es obligatorio".

Es en este contexto en el que se profiere el discurso del presidente KENNEDY, que hoy concebimos como el florecimiento del Derecho del consumo. Esto es, en un momento en el que hay un cambio de paradigma en el mundo y las legislaciones empiezan a desplazar sus centros gravitacionales desde el acatamiento del principio de legalidad, hacia el respeto por instituciones como la dignidad humana, el interés general y los derechos sociales, se produce el reconocimiento del Derecho del consumo como una especie singular del Derecho mercantil, que precisamente busca darle relevancia material a los derechos e intereses del consumidor como colectivo, lo cual evidencia que a partir de ese momento histórico en el mundo, el resto de normas que regulan aspectos mercantiles como la propiedad industrial y la competencia se interpretan en función, ya no de sus protagonistas que bien podrían ser los empresarios e incluso el Estado en su faceta de regulador del mercado, sino de un bien jurídico superior que se torna en eje central del modelo: la dignidad de las personas y sus derechos.

Con base en lo anterior, consideramos valioso volver la mirada hacia la evolución histórica de conceptos como el de libre competencia y al desarrollo de disciplinas del Derecho, como la competencia desleal o la propiedad industrial, para efectos de evidenciar cómo, aun cuando es posible que en el origen de estas materias no se contemplara el consumidor y sus derechos como el principal bien jurídico a proteger, lo cierto es que el proceso de modernización del Derecho y sus instituciones, marcado por las luchas sociales que dieron lugar a la reivindicación de cartas de derechos fundamentales mucho más robustas, así como por las legislaciones posguerra que volvieron la mirada hacia el respeto por la dignidad humana, terminan instituyendo al consumidor como eje principal que sustenta el desarrollo moderno de estas disciplinas del Derecho mercantil, una especie de prisma a través del cual se interpretarían de forma más adecuada, o mejor, más justa, las normas que regulan los diferentes entornos mercantiles. 
En este mismo sentido, también es importante apreciar cómo se materializan estos principios en los actuales ordenamientos de competencia y propiedad industrial de los países de la Comunidad Andina de Naciones (CAN), a la que pertenece Colombia, con el ánimo de evidenciar que también en estos la figura del consumidor irradia la configuración de las normas y así apreciar la manera en que estas legislaciones se han aproximado, desde las especialidades jurídicas antes enunciadas, a la protección de los derechos del consumidor como eje central del modelo.

\section{EL DERECHO DE LA COMPETENCIA Y LA PROTECCIÓN DEL CONSUMIDOR}

\section{Origen y desarrollo del Derecho de la competencia en el Derecho continental europeo}

Según BerCOVITZ, "La regulación moderna contra la competencia desleal surge en el siglo XIX de la mano del liberalismo económico. Ello es así porque una de las conquistas de la Revolución francesa consiste en la denominada libertad de industria y de comercio; dicho en otros términos, en la libertad de competir. Libertad que en etapas históricas anteriores no existía, debido principalmente a la rígida implantación de los gremios ${ }^{\prime \prime}$.

El mismo autor comenta que es durante el siglo XIX que en Francia se dan los primeros pasos hacia la configuración del Derecho de la competencia, por vía de interpretación del artículo que regulaba la responsabilidad extracontractual en el Código Civil Napoleónico y ya en el albor del siglo XX, en 1909, es en Alemania donde surge una Ley que regula específicamente la materia.

Sobre el particular, el tratadista AURELIO MENÉNDEZ, en su obra "La competencia desleal", explica que en esta primera etapa es posible identificar dos modelos: i) el paleoliberal, que termina con la expedición de la Ley Alemana, en 1909, y que bien podría describirse como una etapa en la que casi todo era permitido en materia de competencia, siempre que no se vulnerara el derecho de propiedad industrial y no se infringieran las normas penales; y ii) el modelo profesional, en el que "la disciplina tendrá un carácter privado y estará encaminada a reprimir aquellas modalidades competitivas que los empresarios en su conjunto estiman incorrectas" ${ }^{\prime \prime}$.

Viene, entonces, un rezago en Europa en cuanto al surgimiento del Derecho de la competencia -que es el tema que nos ocupa- gracias a un comienzo del siglo XX convulsionado por la Primera y Segunda Guerra Mundial, lo que contrasta con el nacimiento de esta disciplina en Estados Unidos, en el año 1890, con el Sherman Act ${ }^{5}$.

3 Bercovitz, Alberto, "La competencia desleal", en Derecho de los Negocios, año 3, n. ${ }^{\circ} 20$, Madrid. Citado en Baldo Kresalja R., Comentarios al Decreto Ley 26122 sobre represión de la competencia desleal, 1992.

4 MenÉndez, Aurelio, La competencia desleal, Ed. Civitas, Madrid, p. 96, 1998.

5 The Sherman Antitrust Act de 1890 (15 U.S.C.A. $\$ \S 1$ et sed.) 
Así las cosas, el moderno Derecho de la competencia europeo tiene su referente inicial en Alemania, pues es allí, con posterioridad a la Primera Guerra Mundial, donde los nazis se encargaron de crear carteles disciplinando prácticamente todas las variables de competencia, al punto de que, en 1933, más específicamente el 15 de julio, se llegó a proferir una norma que imponía a los empresarios el deber de formar carteles. Tal como lo describe KARTTE, "la economía deja de estar al servicio de la satisfacción libre de las necesidades humanas y es utilizada para implantar un imperio en menosprecio del hombre y de la libertad"6.

Es solo hasta después de la Segunda Guerra Mundial que tiene lugar la creación de normas orientadas específicamente a defender la libre competencia y se inicia el desarrollo de la disciplina por parte de las potencias europeas, comenzando por Alemania, en donde, por obvias razones, se imponía la necesidad de desmontar el esquema monopolístico implementado por los nazis, por lo que "en el acuerdo de Potsdam de 1945, se preveía la descentralización de la economía alemana y, bajo la presión de EEUU, el 1 de enero de 1958 entró en vigor la Gesetz gegen Wettbewerbsbeschränkungen (GWB), Ley contra las Restricciones de la Competencia"7.

El fin de la Segunda Guerra Mundial trajo consigo la necesidad de reactivar la economía y, con ello, la incorporación del modelo social en la disciplina jurídica de la competencia, con cambios en aspectos sustanciales de lo que, hasta ese momento, se concebía como regulación de la competencia, ya que, por ejemplo, "En relación con el objeto de protección se observa el paso de una concepción centrada en la tutela de los intereses individuales de los competidores a una concepción fundada en la protección del orden económico del mercado en función del interés privado de los competidores, el interés colectivo de los consumidores y el interés público del Estado. En el plano de los criterios de enjuiciamiento se advierte también una notable transformación: la deslealtad deja de ser primariamente entendida como un juicio de incorrección profesional, ensayado en atención a las normas morales o convencionales de la clase empresarial, para convertirse en juicio de inadecuación a los principios del ordenamiento económico (libre competencia, tutela del consumidor, etc.). Finalmente, en la cuestión relativa a las prácticas reprimidas, se advierten así mismo algunos cambios importantes: ciertas actividades anteriormente consideradas como desleales (sirvan de ejemplo la publicidad comparativa o la invasión de zona de exclusiva), comienzan a permitirse en atención a los efectos beneficiosos que pueden producir desde el punto de vista de los intereses de los consumidores y del interés público en la conservación de un mercado altamente competitivo; por el contrario, ciertas prácticas permitidas (como pueden ser la venta a bajo coste, la publicidad engañosa, o las ventas agresivas) se someten a una nueva estimación en respuesta a la primacía de los valores o intereses ahora dominantes (...) A todo ello se suma el desarrollo, por parte del Estado, de una política de tutela reforzada

6 KARTTE, W. Leyes sobre la competencia. Materiales sobre política y sociedad en la RF Alemana, citado por CASES, L1., op. cit., p. 658, 1990.

7 Alcaide Guindo, CRistina, La evolución de la política de defensa de la competencia, p. 247. 
del consumidor como parte débil de las relaciones del mercado. En síntesis, se presentan dos factores decisivos que explican las nuevas orientaciones en esta materia: la asunción, por parte del Estado, de una política de defensa de la competencia, abandonada -hasta entonces- al libre juego de los sujetos económicos participantes en el mercado, así como de una política de tutela del consumidor confiada también hasta entonces al mercado" ${ }^{\prime \prime}$.

Así las cosas, el Derecho de competencia ha evolucionado, dejando de ser un conjunto de normas concebidas para resolver conflictos entre comerciantes y preservar los etéreos intereses del Estado representados en la estabilidad del mercado, para convertirse en una herramienta fundamental de cara a la defensa de los derechos e intereses de los consumidores.

\section{Actualidad del Derecho de la competencia}

\subsection{Europa}

En materia de competencia, llama la atención la existencia de la Directiva 2005/29/CE del Parlamento Europeo y del Consejo, del 11 de mayo de 2005, que regula de manera específica las prácticas comerciales desleales de las empresas en sus relaciones con los consumidores en el mercado interior. Esto es, que se tipifican conductas desleales, ya no en función de las relaciones profesionales entre comerciantes (modelo profesional), sino en función de las relaciones de dichos empresarios con los consumidores.

Así, el primer considerando de dicha norma plantea de entrada que el Artículo 153, apartado 1, y apartado 3, letra a), del Tratado establecen que la Comunidad contribuirá a que se alcance un alto nivel de protección de los consumidores mediante las medidas que adopte en virtud del Artículo 95 del mismo Tratado.

Así mismo, la fisionomía social de la norma se puede apreciar en el considerando octavo (8), en el cual se plantea que la Directiva en cuestión protege directamente los intereses económicos de los consumidores frente a las prácticas comerciales desleales de las empresas en sus relaciones con los consumidores. Por lo tanto, protege también indirectamente a las empresas que operan de manera lícita. Es decir, que en este esquema de protección, lo que se busca es la de los intereses de los consumidores y, como un efecto derivado o indirecto, se considera la defensa de los intereses de las empresas que compiten lícitamente en el mercado, con lo cual se pone de manifiesto el aspecto social del modelo.

Posteriormente, la norma se ocupa de la descripción típica de las conductas desleales de los empresarios en sus relaciones con los consumidores, caracterizando actos referidos a temas como el engaño, por acción u omisión, y las prácticas agresivas en relación con los consumidores, como el acoso, la coacción, incluido el uso de la fuerza, o la influencia indebida, la libertad de elección o conducta del consumidor medio con respecto al 
producto (...) en los casos en que dichas acciones puedan hacer que el consumidor tome decisiones de compra que de otra forma no hubiera tomado.

\subsection{Comunidad Andina}

En materia de competencia a nivel andino, la Decisión 486 regula la competencia desleal vinculada a la propiedad industrial, tal como hemos mencionado previamente. Así mismo, cada país ha desarrollado sus ordenamientos internos en materia de competencia; para efectos de este escrito, es importante destacar que las Constituciones de los países de la CAN, excepto la de Bolivia, se refieren directamente a la garantía de los derechos de los consumidores y consagran principios como la libertad de empresa y libertad de competencia.

\section{Bolivia}

Los arts. 66 a 71 del Código de Comercio boliviano, contenidos en el capítulo V (Competencia desleal), del Título I (De los comerciantes) del Libro I (De los comerciantes y sus obligaciones) se refieren a la competencia como tal y se remiten directamente al Código Penal. Adicionalmente, otras normas del Código de Comercio se relacionan con este tema: en el Art. 21, se establece que en delitos de competencia desleal, la sanción comprenderá inclusive la prohibición para ejercer el comercio, y en el Art. 25 se consagra la obligación del comerciante de abstenerse de ejecutar actos de competencia desleal.

Es esta la reglamentación boliviana que más se aproxima al tema de competencia desleal, hoy por hoy. Ahora bien, es preciso señalar que el antecedente más reciente en relación con el tema de libre competencia es el Decreto Supremo 29519 de abril de 2008, que tiene por objeto regular la competencia y la defensa del consumidor frente a conductas lesivas que influyan negativamente en el mercado provocando especulación en precios y cantidad, lo que deja ver el vínculo directo que concibe el legislador al momento de dar vida a esta norma entre las Conductas Anticompetitivas y los nocivos efectos de las mismas de cara a los intereses de los consumidores, siendo entonces viable concluir que, al menos en su concepción, las primeras aproximaciones en Bolivia a la normatividad en materia de libre competencia, le han dado relevancia sustancial a la figura del consumidor.

\section{Colombia}

Partiendo de las disposiciones del Convenio de París, en Colombia, las prácticas de competencia desleal se encuentran tipificadas en la Ley 256 de 1996. En ella se caracterizan conductas como el engaño (Art. 11 ... toda conducta que tenga por objeto o como efecto inducir al público a error sobre la actividad, las prestaciones mercantiles o el establecimiento ajenos...), la confusión (Art. 10 .. toda conducta que tenga por objeto o como 
efecto crear confusión con la actividad, las prestaciones mercantiles o el establecimiento < sic > ajenos) la comparación (Art. 13 ... se considera desleal la comparación pública de la actividad, las prestaciones mercantiles o el establecimiento propios o ajenos con los de un tercero, cuando dicha comparación utilice indicaciones o aseveraciones incorrectas o falsas, u omita las verdaderas...) o la imitación (Art. 14... la imitación exacta y minuciosa de las prestaciones de un tercero se considerará desleal cuando genere confusión acerca de la procedencia empresarial de la prestación...).

Ya desde la exposición de motivos de esta norma se advertía sobre el paso de la protección del interés privado de los competidores en conflicto, a la defensa del interés colectivo de los consumidores e incluso del interés público del Estado a la preservación de un sistema económico de competencia no falseada. Así que estas conductas calificadas típicamente como desleales tienen evidente relación con la protección de los intereses de los consumidores, en la medida en que, además de amparar al competidor de los efectos nocivos de la misma, permiten filtrar del sistema actuaciones que tienen un claro potencial de daño colectivo.

En materia de libre competencia, la Ley 155 de 1959 dicta algunas disposiciones sobre prácticas comerciales restrictivas e incluye algunas normas que propenden a la protección de los derechos e intereses de los consumidores, como el Artículo 3.

Las disposiciones de esta Ley fueron desarrolladas en el Decreto 2153 de 1992, en cuyos artículos 44 y ss. se definen y tipifican las prácticas comerciales restrictivas. Esta norma, modificada por la Ley 1340 de 2009, le atribuye a la Superintendencia de Industria y Comercio la función de velar por la observancia de las disposiciones sobre protección de la competencia; atender las reclamaciones o quejas por hechos que pudieren implicar su contravención y dar trámite a aquellas que sean significativas para alcanzar en particular los siguientes propósitos: la libre participación de las empresas en el mercado, el bienestar de los consumidores y la eficiencia económica.

En este sentido, la Ley 1340 de 2009, proferida con el objeto de actualizar la normatividad en materia de protección de la competencia, contiene disposiciones que dejan ver su talante garantista de los derechos de los consumidores, incluyendo normas como la del Artículo 12, que modifica el Artículo 51 del Decreto 2153 de 1992, estableciendo la denominada "excepción de eficiencia" mediante la cual "La autoridad nacional de competencia podrá no objetar una integración empresarial si los interesados demuestran dentro del proceso respectivo, con estudios fundamentados en metodologías de reconocido valor técnico que los efectos benéficos de la operación para los consumidores exceden el posible impacto negativo sobre la competencia y que tales efectos no pueden alcanzarse por otros medios".

Finalmente, el Artículo 19 de esta Ley dispone que los consumidores tienen el carácter de terceros interesados y pueden intervenir en las investigaciones aportando las consideraciones y pruebas que pretendan hacer valer para que la Superintendencia de Industria y Comercio se pronuncie en uno u otro sentido. 


\section{Ecuador}

En Ecuador, el hito reciente en esta materia es la emisión de la Ley Orgánica de Regulación y Control de Poder de Mercado, de octubre de 2011. El objeto de la ley es evitar, prevenir, corregir, eliminar y sancionar el abuso de operadores económicos con poder de mercado ${ }_{i}$ la prevención, prohibición y sanción de acuerdos colusorios y otras prácticas restrictivas; el control y regulación de las operaciones de concentración económica, y la prevención, prohibición y sanción de las prácticas desleales, buscando la eficiencia en los mercados, el comercio justo y el bienestar general y de los consumidores y usuarios, para el establecimiento de un sistema económico social, solidario y sostenible.

$\mathrm{Al}$ igual que en el caso colombiano, la Ley Orgánica de Ecuador tipifica actos desleales que, como ya hemos visto, tienen relación directa con la protección de los consumidores, tales como confusión, engaño, imitación y comparación, introduciendo una categoría específica de acto desleal denominada "prácticas agresivas contra los consumidores". Adicionalmente, la norma regula temas relacionados con la libre competencia, como el abuso del poder de mercado y los acuerdos y prácticas restrictivas, partiendo de la premisa consistente en que "el Artículo 283 de la Constitución de la República establece que el sistema económico es social y solidario; reconoce al ser humano como sujeto y fin, propende a una relación dinámica y equilibrada entre sociedad, Estado y mercado, en armonía con la naturaleza, y tiene por objeto garantizar la producción y reproducción de las condiciones materiales e inmateriales que posibiliten el buen vivir".

Perú

Mediante el Decreto Legislativo 1044 del 26 de junio de 2008, se aprobó la nueva Ley de Represión de la Competencia Desleal. Este Decreto Legislativo unifica las disposiciones de competencia desleal, las normas sobre publicidad, que anteriormente estaban reguladas en el Texto Único Ordenado del Decreto Ley 26122, Ley de Represión sobre la Competencia Desleal (la "LRCD") y en el Texto Único Ordenado del Decreto Legislativo 691, Normas de la Publicidad en Defensa del Consumidor (la LPDC), respectivamente.

La ley tipifica actos desleales que, como ya hemos visto, tienen relación directa con la protección de los consumidores, tales como confusión, engaño, imitación y comparación. Adicionalmente, contiene un subcapítulo que regula de manera específica "Actos de competencia desleal desarrollados mediante la actividad publicitaria", dentro de los cuales se incluyen categorías muy interesantes de actos desleales que tienen una clara vocación tutelar frente a los derechos de los consumidores, tales como:

- El Artículo 16: Actos contra el principio de autenticidad, dentro de los cuales se encuentra la publicidad encubierta;

- El Artículo 17: Actos contra el principio de legalidad, en el que básicamente se eleva a la categoría de actos de competencia desleal algunas violaciones concretas de los derechos de los consumidores frente a la publicidad, como "omitir la advertencia a 
los consumidores sobre los principales riesgos que implica el uso o consumo de productos peligrosos anunciados" u "omitir la presentación del precio total de un bien o servicio sin incluir los tributos aplicables y todo cargo adicional indispensable para su adquisición, cuando el precio es anunciado".

\section{LA PROPIEDAD INDUSTRIAL Y LA PROTECCIÓN DE LOS CONSUMIDORES}

$\mathrm{Al}$ igual que en el caso del Derecho de la competencia, el antecedente del cual se deriva nuestra normatividad en materia de propiedad industrial se encuentra en el Derecho continental europeo, por lo cual es preciso enfocar el análisis en dicho modelo:

\section{Origen y desarrollo de la propiedad industrial en el Derecho continental europeo}

En materia de propiedad industrial, la Revolución Francesa es el hito que parte la historia en dos. Hasta ese momento se concebía la posibilidad de adquirir ciertas prerrogativas respecto de una invención o desarrollo novedoso logrado, pero estas siempre debían ser concedidas por el rey, generando injusticias y tratos desiguales en relación con los verdaderos creadores o desarrolladores de la innovación, pues no es lo mismo un privilegio que un derecho. Así las cosas, uno de los objetivos de la Revolución Francesa fue precisamente suprimir los privilegios reales y, para el efecto, mediante la Ley de la Asamblea Nacional de 4 de agosto de 1789, efectivamente se suprimieron todos los privilegios y prerrogativas que crearan diferencias arbitrarias dentro de la sociedad ${ }^{9}$.

El 31 de diciembre de 1790, se profirió el Decreto que se refería específicamente a la materia en los siguientes términos: "La Asamblea Nacional, considerando que toda idea nueva cuya manifestación ó desarrollo pueda llegar a ser útil a la sociedad, pertenece primitivamente a aquel que la ha concebido, y que el no considerar un descubrimiento industrial como de propiedad de su autor, sería atacar en su esencia los derechos del hombre, decreta: Artículo $1^{\circ}$. Todo descubrimiento ó nueva invención en todo género de industrias es propiedad de su autor ${ }^{\prime \prime} 10$.

Es así como, "con el advenimiento del Liberalismo, a partir de la Revolución Francesa, de la organización del sistema político de los Estados Unidos y de la extensión de las revoluciones liberales por todo el mundo, se debate y formula verdadera legislación moderna sobre propiedad intelectual e industrial (1790 en EE. UU y 1791 en Francia). A partir de ahí, la protección ha ido extendiéndose, evolucionando y diversificándose para cubrir áreas geográficas cada vez más grandes así como nuevas modalidades. De hecho, a finales del siglo XIX, prácticamente no había país importante que no hubiera adoptado 
leyes sobre propiedad industrial, abriendo la puerta a la protección de la actividad inventiva (patentes), los signos distintivos (marcas) o el diseño industrial"11.

Como vemos, la concepción moderna en cuanto a esta materia tiene inicialmente como eje el respeto por uno de los atributos de la personalidad, como lo es su expresión creativa; es decir, se empieza por reconocer el derecho a la propiedad intelectual de manera genérica $y$, posteriormente, este reconocimiento se va especializando en las diferentes legislaciones, haciéndose las primeras distinciones entre el Derecho de propiedad intelectual, en abstracto, y la propiedad industrial como un género de esta especie de derechos. Se logra, entonces, claridad sobre la relevancia de los derechos de propiedad industrial como una herramienta que ya no solo permite reconocer al inventor su derecho personal y subjetivo a reivindicar y explotar económicamente su papel de innovador, sino que permite dinamizar y estabilizar los mercados, generando entornos de competencia saludables.

Con el auge de la industria y el incremento de los intercambios comerciales entre países, durante el siglo XIX surge la necesidad de crear un instrumento para facilitar la protección de los derechos de propiedad industrial a nivel internacional y así, en 1883, se suscribe el Convenio de París para la Protección de la Propiedad Industrial (norma que posteriormente determinaría el contenido de las legislaciones latinoamericanas desarrolladas durante el siglo XX).

Pese a que el Convenio de París es una norma eminentemente comercial enfocada en la manera como se reconocen los derechos de propiedad industrial a nivel internacional, incorporando principios como el de "trato nacional", que implica que los nacionales de los países integrantes de la Unión recibirán de parte de los demás Estados miembros la posibilidad de gozar de todos los privilegios que sean concedidos a los nacionales del respectivo país, es claro que en ella también se contemplan con claridad herramientas de protección para los derechos de los consumidores como colectivo, las cuales ponen en evidencia el trasfondo social de esta disposición.

Entre otras, el Convenio proscribe el registro de marcas "cuando sean contrarias a la moral o al orden público y, en particular, cuando sean capaces de engañar al público", plantea que es posible emplear una misma marca en relación con productos o servicios diferentes "en tanto que dicho empleo no tenga por efecto inducir al público a error y que no sea contrario al interés público", e incorpora instituciones como la de las licencias obligatorias en materia de patentes que permiten a cada uno de los países miembros de la Unión "tomar medidas legislativas, que prevean la concesión de licencias obligatorias, para prevenir los abusos que podrían resultar del ejercicio del derecho exclusivo conferido por la patente", en clara protección de los derechos de los consumidores y la comunidad en general. Así mismo, el Artículo 10bis regula temas de Competencia Desleal en materia de propiedad industrial, catalogando como tal, entre otros, "cualquier acto capaz 
de crear una confusión, por cualquier medio que sea, respecto del establecimiento, los productos o la actividad industrial o comercial de un competidor".

\section{Actualidad de la propiedad industrial}

\subsection{Europa}

En materia de propiedad industrial, y específicamente en materia de marcas, el Reglamento (CE) n. ${ }^{\circ}$ 207/2009 del Consejo de 26 de febrero de 2009 sobre la marca comunitaria establece criterios que los países miembros deben seguir en el diseño de sus legislaciones internas en cuanto a esta materia. El Reglamento incluye aspectos como la creación de la Oficina de Armonización del Mercado Interior (marcas, diseños y modelos) y la delimitación del concepto de Capacidad Jurídica, con base en el cual se identifican las personas que se encuentran en posición de ser titulares de derechos marcarios. Más allá de esto, la norma incluye disposiciones en las que se establecen criterios aplicables al registro de marcas, las cuales buscan proteger esencialmente a los consumidores.

De entrada, la parte considerativa de esta norma plantea que "Procede interpretar la noción de similitud en relación con el riesgo de confusión. El riesgo de confusión, cuya apreciación depende de numerosos factores y, en particular, del conocimiento de la marca en el mercado, de la asociación que pueda hacerse entre ella y el signo utilizado o registrado, del grado de similitud entre la marca y el signo y entre los productos o servicios designados, debe constituir la condición específica de protección".

Ya en el cuerpo de la norma, en clara consonancia con esta consideración inicial, se incluyen disposiciones tendientes a cumplir con este postulado, así:

- El Artículo 7 consagra las causales de denegación absolutas, mencionando que se debe denegar de plano el registro de marcas que, entre otras, puedan inducir al público a error, por ejemplo, sobre la naturaleza, la calidad o la procedencia geográfica del producto o servicio.

- El Artículo 8 consagra las causales de denegación relativas, mencionando que habiéndose presentado oposición del titular de una marca anteriormente registrada, se denegará el registro de la marca solicitada, entre otras, cuando por ser idéntica o similar a la marca anterior y por ser idénticos o similares los productos o servicios que ambas marcas designan, exista riesgo de confusión por parte del público en el territorio en que esté protegida la marca anterior; el riesgo de confusión incluye el riesgo de asociación con la marca anterior.

Como acabamos de ver, es la propia norma la que indica con claridad cuál es la condición específica de protección de estas disposiciones. En este caso, la normativa comunitaria europea pretende evitar esencialmente el riesgo de confusión, lo que evidentemente deriva en una protección efectiva para los empresarios propietarios de marcas, pero sobre todo 
en la garantía de los derechos de los consumidores, quienes, de entre todos los actores del mercado, terminan siendo el más expuesto y afectado con este tipo de conductas.

Así las cosas, es claro que también en materia de propiedad industrial, el Derecho continental termina decantándose por un modelo social que contempla de manera fundamental la protección de los derechos e intereses de los consumidores como colectivo, amparando de esta manera el eje central de la regulación, esto es, la defensa del interés general materializada en la adecuada protección de los derechos de los consumidores. Todos estos principios se encuentran incorporados en la normatividad que se desarrollaría en Colombia y en la región en materia de propiedad Industrial, desde mediados del siglo XX, teniendo como referente histórico la creación de la Comunidad Andina de Naciones en 1966 y el nacimiento de la Decisión 486 de 2000, norma que actualmente regula estos temas a nivel regional.

\section{2. Comunidad Andina}

En los países que hoy día hacen parte del Pacto Andino (Bolivia, Colombia, Ecuador y Perú), la norma que regula los temas de propiedad industrial es la Decisión 486 de 2000. Los antecedentes que marcan la expedición de esta disposición indican que lo que se buscaba con ella era cubrir una necesidad de modernizar la reglamentación que sobre la materia se aplicaba en la región, teniendo como foco principal la regulación del comercio comunitario, sin que el papel del consumidor y sus derechos o intereses ocupara un lugar preponderante en los razonamientos y motivaciones que llevaron a su adopción. En ese sentido, su influencia básica es el Convenio de París que, como ya hemos visto, contempla elementos de defensa de los intereses de los consumidores. Así, la norma en cuestión contiene en su Artículo 61 la figura de las licencias obligatorias en materia de patentes que, como vimos anteriormente, tiene una clara orientación tutelar de los derechos de los consumidores.

En materia de marcas, la protección para los consumidores es la que hemos venido mencionando y que se materializa en aspectos como la imposibilidad de obtener el registros de marcas que puedan engañar a los medios comerciales o al público (Artículo 135, Lit. i.) o las causales de irregistrabilidad relativas contenidas en los literales a), b) y c) del Artículo 136, que prohíben el registro de signos que sean idénticos o se asemejen a marcas, nombres comerciales y lemas comerciales previamente solicitados o protegidos a nombre de un tercero, cuando el uso del signo solicitado pueda causar un riesgo de confusión o de asociación.

De otro lado, la norma, en su Título XVI, regula lo relacionado con "La Competencia Desleal Vinculada a la Propiedad Industrial", tipificando como desleales conductas como: "a) cualquier acto capaz de crear una confusión, por cualquier medio que sea $(. .$.$) ".$ Sobre el particular, el Tribunal de Justicia de la Comunidad Andina, en la interpretación prejudicial del literal a) del Artículo 259 de la Decisión 486 de la Comunidad Andina, ha establecido que "Los actos de competencia desleal por confusión no se refieren propiamente al análisis de confundibilidad entre los signos distintivos de los productos de 
los competidores, toda vez que tal situación se encuentra sancionada por un régimen específico, sino a la confusión que aquellos actos pudieran producir en el consumidor".

Otras disposiciones, como el literal n) del Artículo 135, el cual prohíbe de manera absoluta el registro de marcas que reproduzcan o imiten signos de conformidad con normas técnicas, tienen orientación protectora frente a los consumidores por las claras implicaciones que tienen este tipo de prácticas en materia de seguridad de los consumidores.

\section{COMENTARIO FINAL}

Con base en lo anterior, es claro que, en el desarrollo histórico de disciplinas del Derecho de estirpe mercantil, como la propiedad industrial, la competencia desleal o la libre competencia, termina por conformarse una especie de triada integrada, de un lado, por el interés de los competidores; del otro, por el interés público del Estado y, en la zona medular, por el interés colectivo de los consumidores.

No en vano en un Estado Social de Derecho como el nuestro, la totalidad del ordenamiento jurídico descansa sobre la concepción de la dignidad humana como eje y razón de ser del modelo. Así que, a la luz de este raciocinio, resulta preciso sostener que de los elementos esenciales de las diferentes disciplinas del Derecho mercantil (interés de los competidores, interés público del Estado e interés colectivo de los consumidores), ninguno es tan relevante como el interés del consumidor, por su relación directa con la noción de dignidad humana. De hecho, a partir de este planteamiento, se encuentra que los dos elementos que le acompañan derivan su existencia precisamente de la tutela de aquel, toda vez que el mercado y el propio Estado, al ser analizados como instituciones que constituyen objetos de protección de las normas, claramente carecen de sentido sin la figura preponderante del consumidor.

No basta, entonces, simplemente, hacer menciones vacías a la protección de los derechos de los consumidores en las normas y los pronunciamientos judiciales y administrativos correspondientes, como si se tratara de un saludo a la bandera que, de manera protocolaria, debe incluirse en los análisis hechos en relación con estos temas. Es menester que este elemento central en el diseño de la legislación mercantil deje de ser una figura conceptual y retórica para convertirse en un verdadero criterio de interpretación y aplicación de las normas que alimentan disciplinas del Derecho, como la competencia y la propiedad industrial.

Y es que uno de los mayores avances de la humanidad, sin duda, es el haber logrado que, al menos en lo conceptual, la mayoría de los modelos de Estado hoy día tengan como eje central la noción de la dignidad humana y el respeto por los derechos fundamentales de las personas. Este trascendental logro se vería menoscabado si las autoridades encargadas de interpretar y aplicar las normas de propiedad industrial, competencia desleal o libre competencia obraran con liviandad al momento de proteger efectivamente los derechos e intereses de los consumidores, entendiendo que, no en pocas ocasiones, las conductas concurrenciales contrarias a dicho tipo de normas coinciden con violaciones 
de las normas de protección al consumidor, con lo cual se termina poniendo en riesgo derechos de estirpe constitucional y fundamental.

Piénsese, por ejemplo, en la ejecución de actos mercantiles tendientes a engañar a los consumidores en relación con las propiedades de un producto alimenticio, induciendo a las personas a consumir dicho alimento absteniéndose de acudir al especialista médico, con la promesa de que el alimento es suficiente para prevenir o incluso curar una determinada patología. Sin duda, se trata de conductas que afectan los derechos de los competidores de este empresario, en la medida en que es muy probable que el infractor logre adquirir ventajas comerciales injustas derivadas de este comportamiento. Sin embargo, es claro que, al hacer un ejercicio de ponderación, el potencial riesgo en que se pone a los consumidores constituye una lesión efectiva a un bien jurídico de mayor estimación en nuestro modelo de Estado, como lo es el interés general representado en la masa de consumidores potencialmente afectados con este comportamiento.

En este mismo sentido, la infracción de un signo distintivo, aun cuando evidentemente lesiona los derechos de propiedad industrial de un tercero, podría llevar a los consumidores a adquirir productos que no cumplan con los mismos estándares de calidad y/o seguridad de los bienes identificados con la marca transgredida, generando riesgos para la salud e integridad de las personas, por lo que, independientemente de la reclamación que pueda realizar el empresario afectado en sus derechos de propiedad industrial, en un análisis juicioso y orientado verdaderamente a la materialización de las normas aplicables en esta disciplina del Derecho mercantil, el operador jurídico debe plantearse la posibilidad de adoptar medidas que, más allá de amparar los derechos de propiedad industrial lesionados, procuren también una protección efectiva de los derechos de los consumidores que hayan podido resultar afectados.

Así las cosas, no es admisible que, en disciplinas del Derecho como la propiedad industrial, la competencia desleal o la libre competencia, se pierda de vista al consumidor y sus derechos, como norte trazado desde la teleología misma de estas disciplinas, para dar lugar a análisis que, aun cuando luzcan profundos y robustos en relación con los aspectos mercantiles, resulten superficiales y alejados del verdadero objeto de protección de dichas normas: los consumidores.

BIBLIOGRAFÍA

AlCaide Guindo, CRistina. La evolución de la política de defensa de la competencia, p. 247.

Bercovitz, Alberto (1992). "La competencia desleal", en Derecho de los Negocios, año 3, n. ${ }^{\circ} 20$, Madrid - Citado en BALDO KRESALJA R. - Comentarios al Decreto Ley 26122 sobre represión de la competencia desleal.

BOUFFLERS, RAPPORT. Sesión de 30 de diciembre de 1790

García-Huidobro, Amunátegui, Vladimir (1992). Legislación sobre Propiedad Industrial. Análisis, jurisprudencia y guía práctica. Editorial Jurídica de Chile. 1. a ed. Santiago de Chile. Julio de 1992.

KARTTE, W. (1990). Leyes sobre la competencia. Materiales sobre política y sociedad en la RF Alemana, citado por CASES, LL., op. cit., p. 658. 
MenÉndeZ, Aurelio (1998). La competencia desleal, Ed. Civitas, Madrid, 96.

SÁiz, PATRicio (UAM) y LobATO, Luis-LuCiO (UCM), Breve bistoria de la propiedad industrial y de su relación con la actividad innovadora.

The Sherman Antitrust Act de 1890 (15 U.S.C.A. §§ 1 et seq.). 